\title{
Downregulation of MTSS1 expression is an independent prognosticator in squamous cell carcinoma of the lung
}

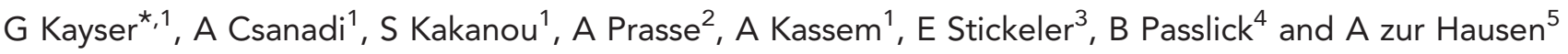 \\ ${ }^{1}$ Department of Surgical Pathology, Institute of Pathology, University Medical Center Freiburg, Breisacher Strasse 115a, D-79106 \\ Freiburg, Germany; ${ }^{2}$ Department of Pneumonology, University Medical Center Freiburg, Kilianstrasse 5, D-79106 Freiburg, \\ Germany; ${ }^{3}$ Department of Gynecology and Obstetrics, University Medical Center Freiburg, Hugstetter Strasse 55, D-79106 \\ Freiburg, Germany; ${ }^{4}$ Department of Thoracic Surgery, University Medical Center Freiburg, Hugstetter Strasse 55, D-79106 \\ Freiburg, Germany and ${ }^{5}$ Department of Pathology, GROW-School for Oncology and Developmental Biology, Maastricht \\ University Medical Center, PO Box 616, NL-6200 MD Maastricht, The Netherlands
}

Background: The metastasis suppressor 1 (MTSS1) is a newly discovered protein putatively involved in tumour progression and metastasis.

Material and Methods: Immunohistochemical expression of MTSS1 was analysed in 264 non-small-cell lung carcinomas (NSCLCs).

Results: The metastasis suppressor 1 was significantly overexpressed in NSCLC compared with normal lung $(P=0.01)$. Within NSCLC, MTSS1 expression was inversely correlated with $\mathrm{pT}$-stage $(P=0.019)$ and histological grading $(P<0.001)$. NSCLC with MTSS1 downregulation $(<20 \%)$ showed a significantly worse outcome $(P=0.007)$. This proved to be an independent prognostic factor in squamous cell carcinomas (SCCs; $P=0.041)$, especially in early cancer stages $(P=0.006)$.

Conclusion: The metastasis suppressor 1 downregulation could thus serve as a stratifying marker for adjuvant therapy in earlystage SCC of the lung.

Lung cancer is one of the leading causes of cancer-related deaths worldwide (Travis et al, 2004; Jemal et al, 2011, 2013). It includes a broad variety of histological subtypes classified either as small-cell lung carcinoma or non-small-cell lung carcinoma (NSCLC). Nonsmall-cell lung carcinoma accounts for more than $80 \%$ of lung cancers and can further be divided into squamous cell carcinoma (SCC), lung adenocarcinoma (LAC), and large-cell carcinoma (LCC). Despite evolving novel treatment regimens, prognosis of NSCLC remains poor and often only palliative treatment options can be offered to the patient. As the major cause of NSCLCassociated mortality is related to distant metastases, there is a need to identify biomarkers possibly predicting aggressive biological behaviour of NSCLC (Pao et al, 2009).

Metastasis suppressor 1 (MTSS1) gene was first described in 2002 by Lee et al who detected that the MTSS1 transcript was missing in tumour cell lines derived from metastatic bladder cancer. Thus, it was first named 'missing in metastasis' (Lee et al, 2002). Initially, MTSS1 was proposed as a potential suppressor protein for metastasis. But functional studies revealed a correlation of MTSS1 to cytoskeleton and actin filament organisation (Mattila et al, 2003; Lee et al, 2007; Mattila et al, 2007). In addition, physiologic MTSS1 expression was recognised during organ development (Glassmann et al, 2007). These findings support that MTSS1 is involved in early carcinogenesis because of an increase in cell motility and invasiveness (Woodings et al, 2003). Using cell culture experiments, Callahan et al were able to show a new function of MTSS1, that is, MTSS1 is able to potentiate the transcription of effector genes of the sonic hedgehog signalling pathway (Callahan et al, 2004). Accordingly, it has been shown that MTSS1 serves as a co-transcription factor by binding to

*Correspondence: Dr G Kayser; E-mail: gian.kayser@uniklinik-freiburg.de

Received 30 September 2014; accepted 22 December 2014; published online 27 January 2015

(c) 2015 Cancer Research UK. All rights reserved 0007-0920/15 
Gli proteins or the Gli-Sufu complex, thereby enhancing gene transcription (Callahan et al, 2004). These findings further support the pro-oncogenic potential of MTSS1. In solid carcinomas of the breast, liver, and bladder, MTSS1 expression has been shown to be negatively correlated with prognostic parameters including patient's survival (Hicks et al, 2006; Ma et al, 2007; Wang et al, 2007; Parr and Jiang, 2009). In order to elucidate the potential prognostic impact of MTSS1 in NSCLC, we investigated its expression in correlation with clinico-pathological parameters including survival. The results obtained from our large and wellcharacterised NSCLC cohort clearly indicate that MTSS1 expression is an independent prognostic factor in NSCLC and may serve as a new potential marker to stratify therapeutic decisions.

\section{PATIENTS AND METHODS}

Patient cohort and tissue multiarray (TMA). Two hundred and sixty-four patients were included in this study after approval by the Institutional Ethics Committee (EK-University Medical Center Freiburg 10/12). All patients were operated with curative intent between 1 January 1990 and 31 August 2007 at the Department of Thoracic Surgery, University Medical Center Freiburg. A summary of the clinico-pathological data is given in Table 1. Samples from malignant and non-neoplastic lung tissues were collected, formalin fixed (24-48 h in $4 \%$ buffered formalin) and paraffin embedded on routine basis. All specimens were evaluated, reclassified by three experienced lung pathologists ( $\mathrm{GK}, \mathrm{AC}, \mathrm{AzH}$ ) according to the current WHO classification (Travis et al, 2004) and re-staged using the latest UICC-TNM classification (7th edition; Sobin et al, 2009). As currently no specific system for the assessment of histological

\begin{tabular}{|c|c|c|}
\hline Age & $\begin{array}{c}\text { 35-83 years } \\
\text { Number }\end{array}$ & $\begin{array}{l}\text { Median: } 65 \text { years } \\
\text { Per cent }(\%)\end{array}$ \\
\hline \multicolumn{3}{|c|}{ Gender } \\
\hline Male & 189 & 72 \\
\hline Female & 75 & 28 \\
\hline \multicolumn{3}{|c|}{ Histologic entity } \\
\hline$A C$ & 91 & 34 \\
\hline SCC & 126 & 48 \\
\hline LC & 47 & 18 \\
\hline \multicolumn{3}{|c|}{ pT category } \\
\hline pT1a & 30 & 11.4 \\
\hline pT1b & 35 & 13.2 \\
\hline pT2a & 90 & 34.1 \\
\hline pT2b & 30 & 11.4 \\
\hline рT3 & 62 & 23.5 \\
\hline pT4 & 17 & 6.4 \\
\hline \multicolumn{3}{|c|}{$\mathrm{pN}$ category } \\
\hline$p N x$ & 5 & 1.9 \\
\hline pNO & 147 & 55.7 \\
\hline pN1 & 40 & 15.1 \\
\hline pN2 & 71 & 26.9 \\
\hline pN3 & 1 & 0.4 \\
\hline
\end{tabular}

\section{UICC stage}

\section{Not assessable}

$1 \mathrm{~A}$

$1 \mathrm{~B}$

2A

$2 B$

$3 \mathrm{~A}$

$3 B$

4

Abbreviations: $\mathrm{AC}=$ adenocarcinoma; $\mathrm{LCC}=$ large-cell carcinoma; $\mathrm{SCC}=$ squamous cell carcinoma. grading is defined and recognised by the WHO (Travis et al, 2004), we assessed histological grade with respect to tumour cell pleomorphy, proliferative activity, and nuclear morphology. In SCC and LAC, a three-tired grading system (G1-well differentiated, G2-moderately differentiated, G3-poorly differentiated) was applied. LCCs were graded as G3. If frequent atypical mitoses, giant and/or spindle cells were present in an appreciable amount, these LCCs were graded as G4.

Discordant cases were discussed and the in common defined consensus was used for subsequent statistical analyses. With respect to tumour heterogeneity three cores of each tumour with a diameter of $2 \mathrm{~mm}$ were transferred into TMA. The tumour cores of pulmonary adenocarcinomas were chosen with respect to heterogeneity of growth patterns encountered. A control set of 33 samples of non-neoplastic lung tissue of the same cohort, that is, alveolar and bronchial areas as well as small peribronchial glands, was also included.

Immunohistochemistry and scoring. Three-micrometre-thick tissue sections were mounted on coated glass slides (Superfrost, Langenbrinck, Emmendingen, Germany) dewaxed and rehydrated in a descending alcohol row. The slides were incubated in target retrieving solution (TRS, DAKO, Hamburg, Germany) for $20 \mathrm{~min}$ at $\mathrm{pH}$ 9. Subsequently, endogenous avidin-biotin was blocked by incubation in biotin-blocking system (DAKO) for $10 \mathrm{~min}$. After washing twice with Tris/saline buffer, monoclonal mouse-anti human MTSS1 antibody (Abcam, Cambridge, UK, ab56780, dilution $1: 600$ ) was applied for $30 \mathrm{~min}$. The sections were then rinsed with Tris/saline buffer and incubated with the secondary biotinilated antibody for $15 \mathrm{~min}$. After activation by streptavidinperoxidase (DAKO) for $10 \mathrm{~min}$, visualisation was performed by 3amino-5-ethylcarbazole. Finally, the slides were counterstained with haematoxylin.

The immunohistochemical stains were analysed as previously described (Kayser et al, 2010, 2011). Specific cytoplasmic MTSS1 expression was evaluated. In single cases, some nuclear positivity could be observed but due to combination with at least moderate cytoplasmic staining intensity it was not separated as a distinct different staining pattern. The total number of positive carcinoma cells within a single core and the total number of NSCLC cells within the same core were counted. For statistical analyses, the percentage of positive tumour cells out of these figures was calculated and rounded to the next decimal. Furthermore, we scored the staining intensity semi-quantitatively $(0=$ negative, no specific staining; $1=$ weak specific staining; $2=$ moderate specific staining; 3 = strong specific staining; Figure 1). To further evaluate immunohistochemical staining patterns, a combined $\mathrm{H}$-score was calculated by multiplying the value of the staining intensity by the percentage of positive tumour cells. The range of the resulting $\mathrm{H}$-score was between 0 and 300 . Mean values of available TMA cores from each patient were used for statistical analyses.

Statistical analysis. For test assessment, distribution of MTSS1 expression was evaluated using the Kolmogorov-Smirnov test. As distribution of MTSS1 expression in our cohort did not prove to be normal, non-parametric statistics including Kruskal-Wallis test and Mann-Whitney U/Wilcoxon test were chosen for evaluation of significant changes of MTSS1 expression in different subgroups. Survival analysis included Kaplan-Meier survival curves and logrank tests for evaluation of statistical significance, as well as multivariate Cox-regression analysis to test for independence of the prognostic value of downregulated MTSS1 expression. The latter included all parameters that proved to be of statistical significance for patient's survival, that is, histological grading, UICC stage, median age (65 years), and MTSS1 downregulation. Statistical analysis was performed using the software package SPSS version 17. Level of significance $\alpha$ was set to $5 \%$ (i.e., $P<0.05$ ). 


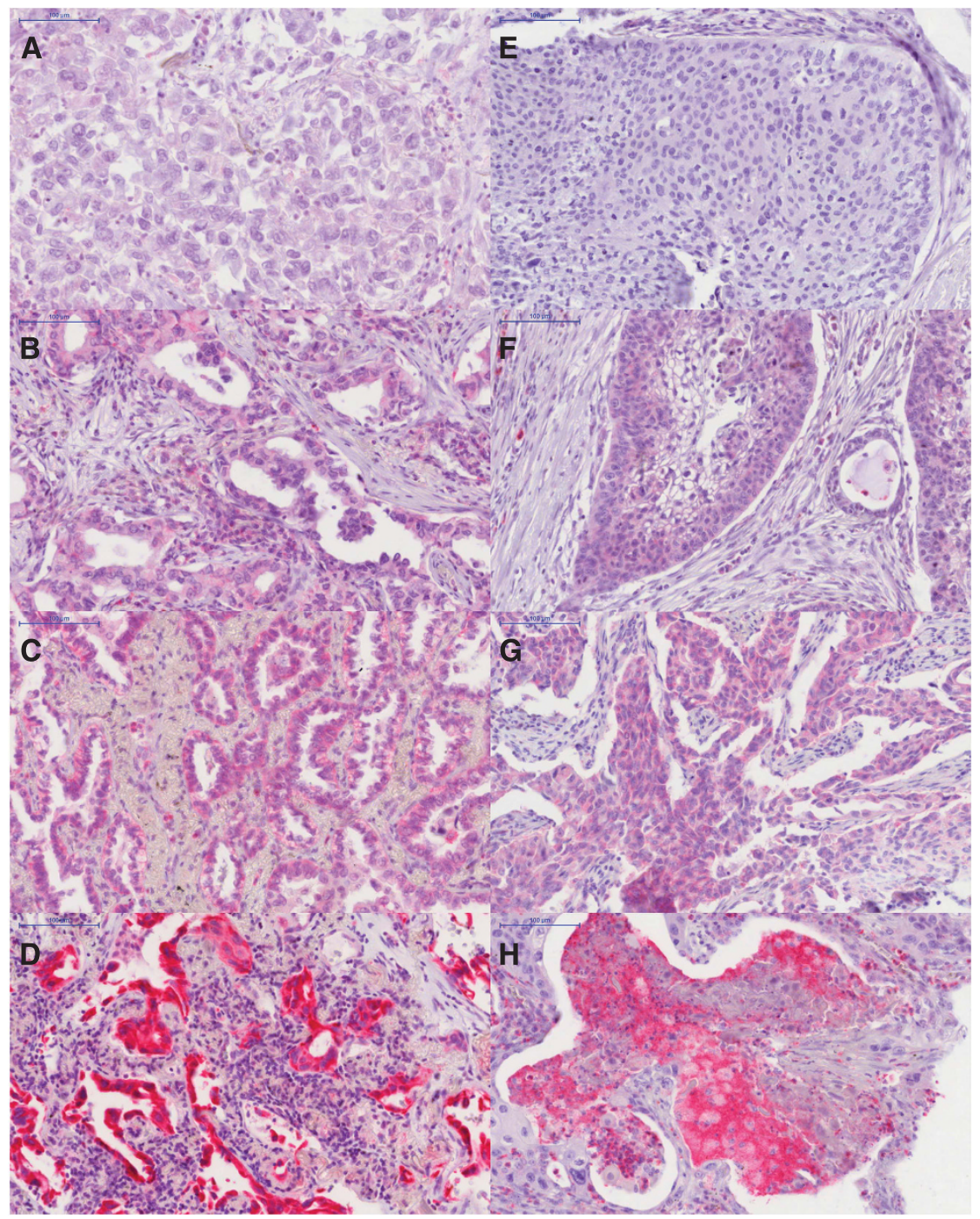

Figure 1. Immunohistological stainings of NSCLC for MTSS1. Left side (A-D): adenocarcinoma (LAC); right side (E-H): squamous cell carcinoma (SCC). (A) LAC without specific cytoplasmatic staining-intensity score $=0$; (B) LAC with weak specific cytoplasmatic staining-intensity score $=1$; (C) LAC with moderate specific cytoplasmatic staining-intensity score $=2$; (D) LAC with strong specific cytoplasmatic staining-intensity score $=3$; (E) SCC without specific cytoplasmatic staining-intensity score =0; (F) SCC with weak specific cytoplasmatic staining-intensity score =1; (G) SCC with moderate specific cytoplasmatic staining-intensity score $=2 ;(\mathrm{H}) \mathrm{SCC}$ strong specific cytoplasmatic staining-intensity score $=3$. Immunostain with MTSS1, objective magnification: $\times 20$.

\section{RESULTS}

MTSS1 is differentially expressed in NSCLC and non-neoplastic lung tissue. Comparing the expression of MTSS1 in nonneoplastic lung tissues and NSCLC, the mean fraction of positive cells was $20 \pm 28 \%$ (standard deviation (s.d.)) in normal controls and increased significantly in carcinoma tissue showing a mean of $36 \pm 33 \%$ (s.d.; $P=0.01$; two-sided Wilcoxon rank test). Analysing staining intensity, non-neoplastic lung tissue showed an intensity score of $0.73 \pm 0.84$ (s.d.) as compared to $0.82 \pm 0.85$ (s.d.) in NSCLC $(P=0.08$; two-sided Wilcoxon rank test). The combined $\mathrm{H}$-score also differed significantly between lung cancers $(60 \pm 71$ (s.d.)) and non-neoplastic lung tissue (39 \pm 47 (s.d.); $P=0.001$, two-sided Wilcoxon rank test).

MTSS1 is differentially expressed in diverse subtypes of NSCLC. The metastasis suppressor 1 expression levels were significantly increased in NSCLC compared with non-neoplastic lung tissues. In addition, also the percentage of MTSS1-expressing tumour cells revealed significant differences between histological NSCLC subtypes. The highest MTSS1 expression was seen in LAC compared with LCC or SCC (Table 2; $P<0.001$ Kruskal-Wallis).

Decrease in MTSS1 expression was almost paralleled by loss of differentiation of NSCLC (Table 2; $P=0.001$ ).

Decrease of MTSS1 expression is associated with advanced tumour stages and metastatic disease. Additional statistical analyses revealed that MTSS1 expression continuously decreased with increasing $\mathrm{pT}$ and $\mathrm{pN}$ stage. This proved to be of statistical significance concerning local tumour spread (percentage: $P=0.016$; intensity: $P=0.021$; H-score: $P=0.014$; Wilcoxon rank test; Table 3). In addition, MTSS1 expression was almost statistically significantly lower in patients presenting with lymph node metastases as compared with those staged pN0 (percentage: $P=0.086$; intensity: $P=0.036$; H-score: $P=0.062$; Mann-Whitney $U$-test; Table 3).

We also analysed MTSS1 expression in correlation with the presence of metastatic disease. As hilar lymph nodes are not infrequently infiltrated by continuous cancer growth and then 
Table 2. Summary of the statistical analysis of MTSS1 expression in correlation with histologic type and grading

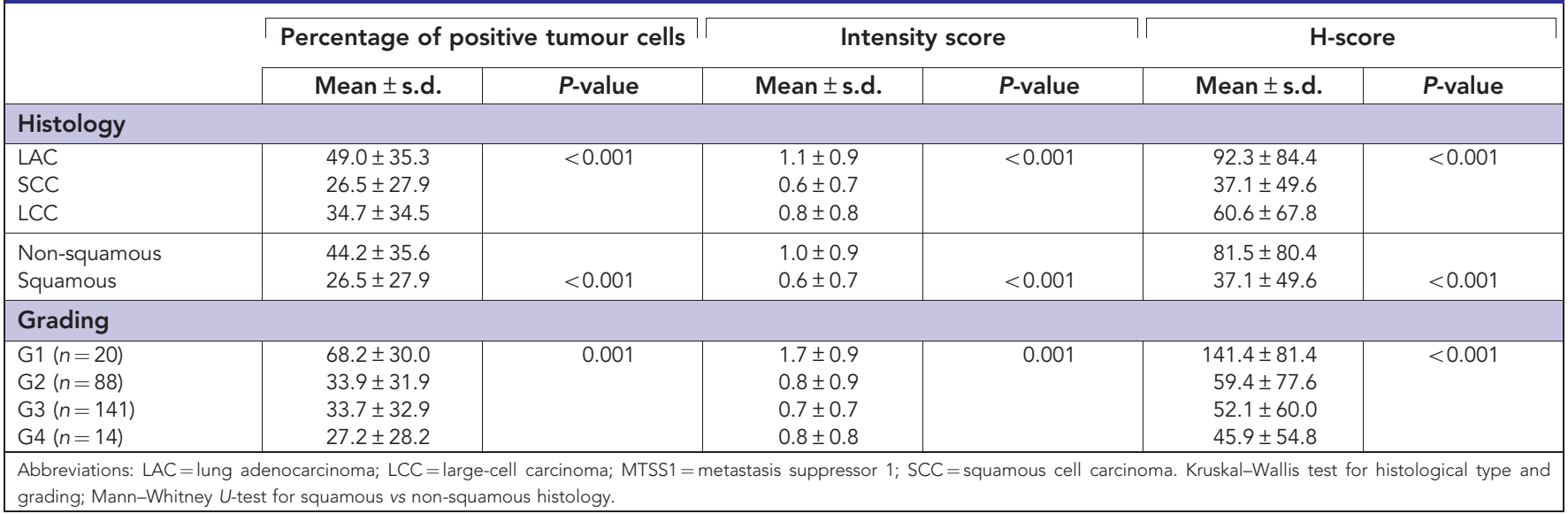

Table 3. Summary of the statistical analysis regarding the correlation of MTSS1 and tumour stage and lymph nodal metastasis status

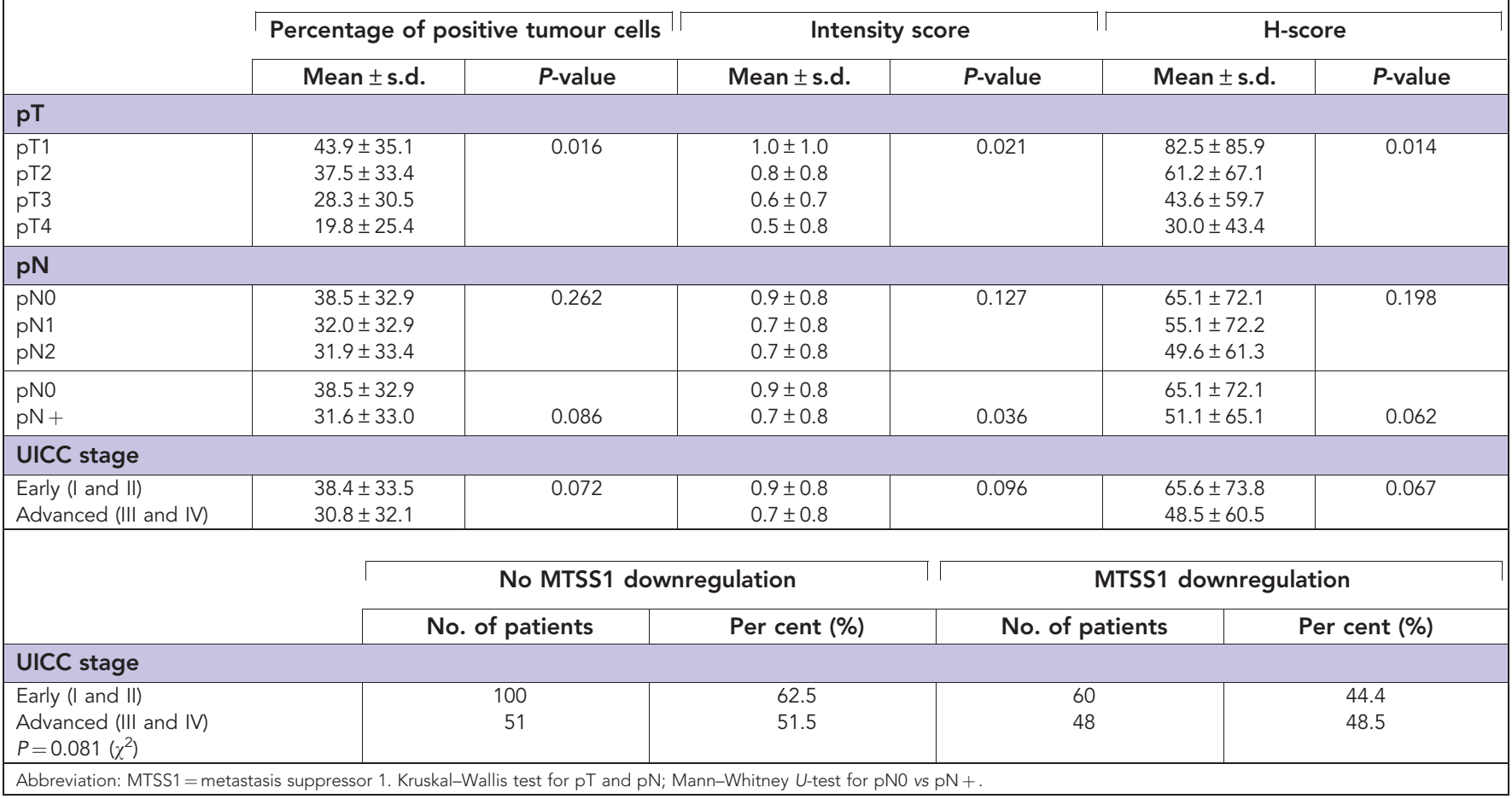

classified as nodal positive, we divided our cohort according to the UICC stages. We dichotomized the cohort into 'early cancer' including the UICC stages I and II as these do not show metastatic spread to mediastinal lymph nodes and 'advanced cancer', which included UICC stages III and IV. In the latter group, metastatic spread can present either as mediastinal lymph node metastasis and/or as separate tumour nodules. Thus, advanced cancer stages III and IV can be assumed as metastatic NSCLC. In early UICC stages I and II, MTSS1 expression was $38.4 \pm 33.5 \%$ (s.d.) at mean and decreased to $30.8 \pm 32.1$ (s.d.) in advanced UICC stages III and IV $(P=0.072$; Mann-Whitney $U$-test; Table 3$)$. In analogy, staining intensity and $\mathrm{H}$-score were decreased in advanced stages, too (intensity: $P=0.096$; H-score: $P=0.067$; Mann-Whitney $U$-test; Table 3).

MTSS1 is an independent prognostic factor in SCCs. Overall survival analysis of our cohort proved to be of representative measures concerning tumour stage, lymph node metastases, and age-related survival as described previously (Kayser et al, 2010, 2011, 2012, 2013).

With regard to the mean fraction of positive cells in normal lung tissue in which in $20 \%$ of cells MTSS1 expression could be detected immunohistochemically, we chose this cutoff for MTSS1 downregulation in cancer tissue, as this event seems to occur later in the time course of biological tumour transformations. NSCLC patients without MTSS1 downregulated tumours had a statistically significant better prognosis compared with those with a fraction of less than 20\% MTSS1-positive tumour cells $(P=0.007$; log rank). As MTSS1 expression was tightly correlated with histological tumour type, this also became evident in subgroup analyses: analysing MTSS1 downregulation with regard to the presence or absence of histologically predominant squamous differentiation, MTSS1 downregulation was of prognostic significance in SCC, only (Figure $2 \mathrm{~A}$ and $\mathrm{B}$ ). 

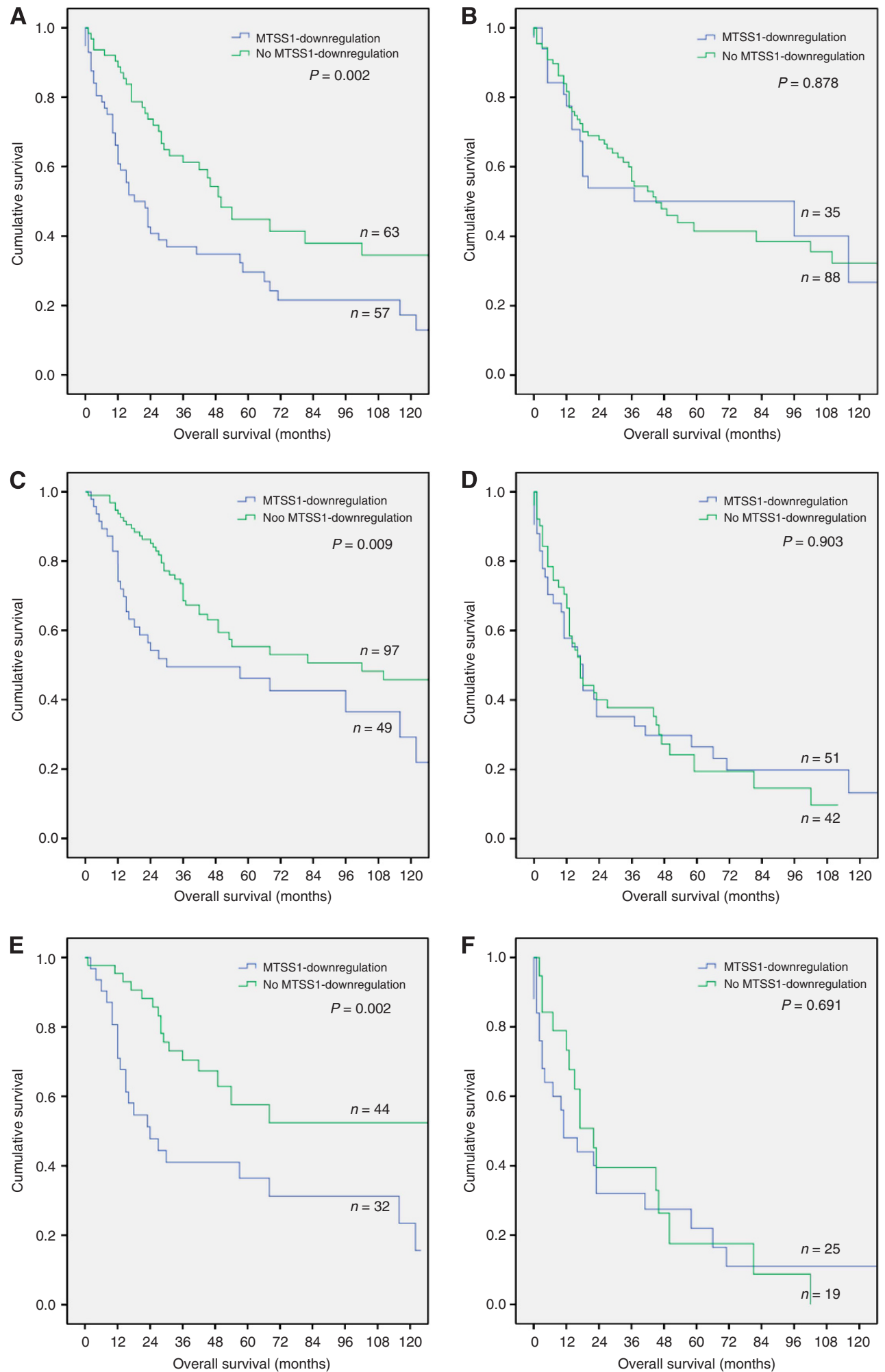

Figure 2. Kaplan-Meier survival plots regarding histological tumour entity (A and $\mathbf{B}$ ) as well as early (C and E) and advanced cancer (D and F) and MTSS1 downregulation. MTSS1 downregulation is a prognostic factor in SCC, the early cancer UICC stages I and II, and especially in early-stage SCC. (A) Squamous cell carcinoma ( $P=0.002$; log rank). (B) Non-squamous NSCLC (LAC and LCC; $P=0.878$; log rank); (C) early UICC stages I and II including the whole cohort ( $P=0.009$; log rank); (D) advanced UICC stages III and IV including the whole cohort $(P=0.903$; log rank); $(E)$ early UICC stages I and II in SCC ( $P=0.002$; log rank); $(F)$ advanced UICC stages in SCC ( $P=0.691$; log rank).

In a multivariate Cox-regression analysis which included all of the prognostically relevant parameters (UICC stage, patient's age (cutoff 65 years (cohort median) and histological grading) beside MTSS1 downregulation, the latter proved to be an independent prognostic factor in SCC $(P=0.019)$, but not in the whole cohort of NSCLC $(P=0.115$; Table 4$)$ or in LAC $(P=0.250)$ or LCC $(P=0.456)$.

MTSS1 downregulation may serve as a predictor for metastasising events. The metastasis suppressor 1 expression was significantly 
Table 4. Multivariate analysis using the Cox-regression algorithm to elucidate an independent impact of MTSS1 downregulation on patient's survival in the whole cohort as well as in early and advanced cancer stages

\begin{tabular}{|c|c|c|c|c|}
\hline & $\begin{array}{c}\text { Hazard ratio } \\
\text { SCC }\end{array}$ & $\begin{array}{c}\text { P-value } \\
\text { SCC }\end{array}$ & $\begin{array}{l}\text { Hazard ratio } \\
\text { Whole cohort }\end{array}$ & $\begin{array}{c}P \text {-value } \\
\text { Whole cohort }\end{array}$ \\
\hline Number of patients & \multicolumn{2}{|c|}{120} & \multicolumn{2}{|c|}{238} \\
\hline UICC stage & 1.92 & $<0.001$ & 1.79 & $<0.001$ \\
\hline Patient's age (cutoff 65 years) & 1.79 & 0.013 & 1.53 & 0.014 \\
\hline MTSS1 downregulation & 1.75 & 0.019 & 1.31 & 0.115 \\
\hline Histological grading & 1.63 & 0.038 & 1.50 & 0.002 \\
\hline \multicolumn{5}{|l|}{ Early cancer } \\
\hline Number of patients & \multicolumn{2}{|c|}{75} & \multicolumn{2}{|c|}{142} \\
\hline $\begin{array}{l}\text { UICC stage } \\
\text { Patient's age (cutoff } 65 \text { years) } \\
\text { MTSS1 downregulation } \\
\text { Histological grading }\end{array}$ & $\begin{array}{l}2.01 \\
2.37 \\
2.43 \\
1.00\end{array}$ & $\begin{array}{l}0.045 \\
0.012 \\
0.008 \\
1.000\end{array}$ & $\begin{array}{l}2.29 \\
1.59 \\
1.80 \\
1.48\end{array}$ & $\begin{array}{l}0.001 \\
0.061 \\
0.020 \\
0.026\end{array}$ \\
\hline \multicolumn{5}{|l|}{ Advanced cancer } \\
\hline Number of patients & \multicolumn{2}{|c|}{44} & \multicolumn{2}{|c|}{93} \\
\hline $\begin{array}{l}\text { UICC stage } \\
\text { Patient's age (cutoff } 65 \text { years) } \\
\text { MTSS1 downregulation } \\
\text { Histological grading }\end{array}$ & $\begin{array}{l}1.83 \\
1.50 \\
1.52 \\
2.46\end{array}$ & $\begin{array}{l}0.577 \\
0.241 \\
0.237 \\
0.020\end{array}$ & $\begin{array}{l}1.24 \\
1.41 \\
1.04 \\
1.47\end{array}$ & $\begin{array}{l}0.588 \\
0.165 \\
0.883 \\
0.058\end{array}$ \\
\hline
\end{tabular}

lower in advanced stages not only concerning absolute figures (Table 3) but also comparing the fraction of cases with respect to MTSS1 downregulation (Table 3).

Furthermore, subgroup analysis of early cancer as well as advanced cancer revealed that the prognostic effect of MTSS1 downregulation is evident in the group of UICC stages I and II, only. Within these early cancer group, MTSS1 downregulation is a predictor of poor patient survival in SCC (Figure 2C-F), contrasting advanced cancer stages III and IV. In these, significant prognostic results could not be observed (Figure 2, Table 4). In the multivariate Cox-regression analysis again, MTSS1 downregulation in early cancer stages proved to be an independent prognostic factor in SCC $(P=0.008$; Table 4$)$.

\section{DISCUSSION}

Lung cancer is still the leading cause of death in patients suffering from malignant disease (Jemal et al, 2011, 2013). Owing to metastatic tumour disease and despite advances in modern chemotherapy regimens, cure from lung cancer is a relatively rare event (Pao, 2012). We aimed to determine the impact of MTSS1 as a new prognostic marker in NSCLC, focussing on a possible association with metastasising events and survival.

Low levels of MTSS1 expression have been reported previously in diverse tissues including lung (Mattila et al, 2003; Bompard et al, 2005). Accordingly, we were able to demonstrate MTSS1 expression in approximately $20 \%$ of non-neoplastic parenchymal cells in lung tissue. MTSS1 upregulation was shown to correlate with malignant transformation, for example, in melanomas and head and neck SCCs (Dawson et al, 2012; Mertz et al, 2014). Ma et al (2007) have shown that an increase of MTSS1 expression parallels the progression of hepatocellular carcinogenesis. However, once hepatocellular carcinoma is established, MTSS1 expression was downregulated.

Here we show that MTSS1 is highly expressed in NSCLC compared with non-neoplastic lung tissues. However, there is a significant diversity of MTSS1 expression between different histological subtypes of NSCLC, which indeed is of clinico-pathological significance: In subgroup analyses, MTSS1 downregulation was particularly important in SCC. Within these, we identified MTSS1 downregulation as a strong and independent prognostic parameter. This supports the observation that SCCs have a different biological profile compared with LACs and LCCs. Recent studies have shown that expression levels of thymidylate synthase are higher in SCCs (Pao and Girard, 2011) and this histological subtype of NSCLC does show a better response to the chemotherapeutic agent gemcitabine as compared with pemetrexed (Scagliotti et al, 2008). Furthermore, Jin et al (2009) detected distinct DNA-methylation and different folate levels in different NSCLC subtypes. In agreement with these studies, our data further support the importance of histological typing with the aim of patient centralised therapy regimes in NSCLC.

In normal lung tissue, highest staining intenstity was observed in alveolar lining cells, especially type II pneumocytes and only to a lesser extend in bronchial epithelium. Basal cells of the bronchi did not show a distinct positive staining for MTSS1. These observations along with the current stem cell theory on the origin of the different histological subtypes of NSCLC (Kotton and Fine, 2008; Eramo et al, 2010) closely correlate with the fact that LACs did show a higher immunohistochemical expression of MTSS1 than SCCs.

In this context, MTSS1 expression is negatively correlated with prognostic clinico-pathological features such as pT, nodal metastasis, or histological grading (Tables 2 and 3). We could observe downregulation of MTSS1 in some NSCLC cases, but mean expression levels even in highly malignant tumours still remained higher than in non-neoplastic lung tissues. This might point out that MTSS1 expression has an important role in the initiation of cancer development and sustaining malignancy. A fact that has been investigated in several studies (Xie et al, 2011b; Du et al, 2012; Mertz et al, 2014) but its functional ways of action have yet not been fully understood (Zhong et al, 2013). Xie et al (2011a) could reproduce the interrelation between downregulation and invasiveness in oesophageal cancer cell lines and Wang et al (2013) reported similar results in cholangiocarcinomas.

Several functions have been attributed to MTSS1, which at least in part might explain the findings of our study: As a multifunctional scaffolding protein MTSS1 is involved in cytoskeleton interaction, especially with actin (Mattila et al, 2003; Woodings et al, 2003; Lin et al, 2005; Lee et al, 2007). This interaction is 
associated with higher motility and invasiveness of tumour cell lines, which is suggestive of faster infiltrative tumour growth and metastatic behaviour (Mattila et al, 2003, 2007; Loberg et al, 2005). Furthermore, a link between the sonic hedgehog signalling pathway and MTSS1 was revealed by Callahan et al (2004): MTSS1 binding to Gli1, Gli2, or the Gli-complex-associated protein Sufu enhances gene expression responsive to sonic hedgehog signalling and leads to promotion of tumour cell growth (Gonzalez-Quevedo et al, 2005). Overexpression of MTSS1 in the carcinogenesis of NSCLC can therefore be explained as MTSS1 is known to promote cell proliferation. This is reflected by our data of MTSS1 overexpression in NSCLC in comparison with non-neoplastic lung tissue. Fujita et al (1997) could show that dysregulation of the sonic hedgehog pathway is more pronounced in squamous cell cancer cell lines as compared with adenocarcinoma cell lines. A finding that was partly reproduced by Huang et al (2010) who revealed different expression patterns of molecules involved in the hedgehog signalling pathway in tumour samples of different histological cell types. These findings in correlation with our data that MTSS1 downregulation is of prognostic value especially in SCC of the lung, again support the importance of accurate histological and immunohistochemical subtyping of NSCLC for prognostic and therapeutic reasons.

Lee et al (2002) first reported MTSS1 in 2002 as a potential metastasis suppressor gene in bladder cancer and named it 'missing in metastasis' as it was not expressed in metastatic cell lines. In our study, we could confirm that MTSS1 is significantly downregulated in metastatic NSCLC with positive regional lymph nodes and in advanced tumour stages. MTSS1 therefore seems to be first overexpressed to promote carcinogenesis and with ongoing tumour progression downregulation of MTSS1 expression according to our data - is associated with a more aggressive biological behaviour. Comparing true metastatic tumour stages III and IV with the early cancer stages I and II in which lymph node involvement is often due to direct invasion of these, our data can reproduce these findings. According to our subgroup analysis, early NSCLC stages not only showed higher expression levels of MTSS1 but also the amount of downregulated NSCLC cases was significantly lower in this group compared with advanced cancer stages (Table 3 ). In addition, this is reflected by our results of the survival analysis, in which MTSS1 downregulation proved to be of prognostic significance. In this respect, MTSS1 expression also has been shown to be a predictor for poor patient survival in breast, liver, upper GI, and bladder cancer patients (Hicks et al, 2006; Ma et al, 2007; Wang et al, 2007, 2013; Parr and Jiang, 2009; Liu et al, 2010; Xie et al, 2011a).

As MTSS1 downregulation was associated with lymph nodal metastases and with the setting of true metastatic events, this protein may also serve as a predictor of metastasising NSCLC. This hypothesis is further supported as MTSS1 downregulation is especially in early cancer stages I and II of significant prognostic value and indicates aggressive biological behaviour of NSCLC, particularly of SCC. Keeping in mind that prognosis in NSCLC is in the vast majority of cases determined by metastatic disease, MTSS1 downregulation can be supposed as an event before the occurrence of metastases. As MTSS1 downregulation proves to be an independent prognostic factor in SCC and this is especially significant in early cancer, it could be clinically useful to stratify these patients into a high- and a low-risk group with the aim to individualise cancer treatment especially in the adjuvant setting. As newly developed small molecules for personalised chemotherapeutic regime are almost exclusively available for NSCLC showing a predominant non-squamous cell differentiation (Pao and Girard, 2011; Pao et al, 2011), investigation of MTSS1 expression could offer new possibilities in the treatment for patients suffering from SCC of the lung.
In conclusion, we demonstrate that MTSS1 is significantly overexpressed in NSCLC compared with non-neoplastic lung tissue. Therefore, it can be assumed that MTSS1 is involved in the carcinogenesis of NSCLC. Furthermore, we show that MTSS1 downregulation is associated with tumour progression and is an independent prognostic parameter in SCC of the lung, particularly in early UICC stages I and II. To the best of our knowledge, this is the first study on MTSS1 expression in NSCLC and includes one of the largest patient cohorts in the study of MTSS1. Based on our results MTSS1 may serve not only as a new prognostic biomarker for NSCLC but also as a putative predictor for metastasising events to occur in early cancer patients. We therefore propose that investigation of MTSS1 downregulation is useful to stratify patients suffering from early-stage NSCLC into different risk groups. Thus, it may also serve as a helpful marker in the decision-making process of additional adjuvant therapy application. Furthermore, owing to its functional activities in actin filament organisation and as a co-transcription factor in the sonic hedgehog signalling pathway (Mattila et al, 2003; Callahan et al, 2004; Mattila et al, 2007), it holds strong potential to open new targeted therapeutic possibilities in personalised cancer treatment regimes.

\section{CONFLICT OF INTEREST}

The authors declare no conflict of interest.

\section{REFERENCES}

Bompard G, Sharp SJ, Freiss G, Machesky LM (2005) Involvement of Rac in actin cytoskeleton rearrangements induced by MIM-B. J Cell Sci 118(Pt 22): 5393-5403.

Callahan CA, Ofstad T, Horng L, Wang JK, Zhen HH, Coulombe PA, Oro AE (2004) MIM/BEG4, a Sonic hedgehog-responsive gene that potentiates Gli-dependent transcription. Genes Dev 18(22): 2724-2729.

Dawson JC, Timpson P, Kalna G, Machesky LM (2012) Mtss1 regulates epidermal growth factor signaling in head and neck squamous carcinoma cells. Oncogene 31(14): 1781-1793.

Du P, Ye L, Li H, Yang Y, Jiang WG (2012) The tumour suppressive role of metastasis suppressor-1, MTSS1, in human kidney cancer, a possible connection with the SHH pathway. J Exp Ther Oncol 10(2): 91-99.

Eramo A, Haas TL, De Maria R (2010) Lung cancer stem cells: tools and targets to fight lung cancer. Oncogene 29(33): 4625-4635.

Fujita E, Khoroku Y, Urase K, Tsukahara T, Momoi MY, Kumagai H, Takemura T, Kuroki T, Momoi T (1997) Involvement of Sonic hedgehog in the cell growth of LK-2 cells, human lung squamous carcinoma cells. Biochem Biophys Res Commun 238(2): 658-664.

Glassmann A, Molly S, Surchev L, Nazwar TA, Holst M, Hartmann W, Baader SL, Oberdick J, Pietsch T, Schilling K (2007) Developmental expression and differentiation-related neuron-specific splicing of metastasis suppressor 1 (Mtss1) in normal and transformed cerebellar cells. BMC Dev Biol 7: 111 .

Gonzalez-Quevedo R, Shoffer M, Horng L, Oro AE (2005) Receptor tyrosine phosphatase-dependent cytoskeletal remodeling by the hedgehogresponsive gene MIM/BEG4. J Cell Biol 168(3): 453-463.

Hicks DG, Yoder BJ, Short S, Tarr S, Prescott N, Crowe JP, Dawson AE, Budd GT, Sizemore S, Cicek M, Choueiri TK, Tubbs RR, Gaile D, Nowak N, Accavitti-Loper MA, Frost AR, Welch DR, Casey G (2006) Loss of breast cancer metastasis suppressor 1 protein expression predicts reduced disease-free survival in subsets of breast cancer patients. Clin Cancer Res 12(22): 6702-6708.

Huang S, Yang L, An Y, Ma X, Zhang C, Xie G, Chen ZY, Xie J, Zhang H (2010) Expression of hedgehog signaling molecules in lung cancer. Acta Histochemica 113(5): 564-569.

Jemal A, Bray F, Center MM, Ferlay J, Ward E, Forman D (2011) Global cancer statistics. CA: Cancer J Clin 61(2): 69-90.

Jemal A, Simard EP, Dorell C, Noone AM, Markowitz LE, Kohler B, Eheman C, Saraiya M, Bandi P, Saslow D, Cronin KA, Watson M, Schiffman M, Henley SJ, Schymura MJ, Anderson RN, Yankey D, 
Edwards BK (2013) Annual Report to the Nation on the Status of Cancer, 1975-2009, featuring the burden and trends in human papillomavirus(HPV)-associated cancers and HPV vaccination coverage levels. J Natl Cancer Inst 105(3): 175-201.

Jin M, Kawakami K, Fukui Y, Tsukioka S, Oda M, Watanabe G, Takechi T, Oka T, Minamoto T (2009) Different histological types of non-small cell lung cancer have distinct folate and DNA methylation levels. Cancer Sci 100(12): 2325-2330.

Kayser G, Csanadi A, Otto C, Plones T, Bittermann N, Rawluk J, Passlick B, Werner M (2013) Simultaneous multi-antibody staining in non-small cell lung cancer strengthens diagnostic accuracy especially in small tissue samples. PLoS One 8(2): e56333.

Kayser G, Kassem A, Sienel W, Schulte-Uentrop L, Mattern D, Aumann K, Stickeler E, Werner M, Passlick B, zur Hausen A (2010) Lactatedehydrogenase 5 is overexpressed in non-small cell lung cancer and correlates with the expression of the transketolase-like protein 1. Diagn Pathol 5: 22.

Kayser G, Schulte-Uentrop L, Sienel W, Werner M, Fisch P, Passlick B, Zur Hausen A, Stremmel C (2012) Stromal CD4/CD25 positive T-cells are a strong and independent prognostic factor in non-small cell lung cancer patients, especially with adenocarcinomas. Lung Cancer 76(3): 445-451.

Kayser G, Sienel W, Kubitz B, Mattern D, Stickeler E, Passlick B, Werner M, Zur Hausen A (2011) Poor outcome in primary non-small cell lung cancers is predicted by transketolase TKTL1 expression. Pathology 43(7): 719-724.

Kotton DN, Fine A (2008) Lung stem cells. Cell Tissue Res 331(1): 145-156.

Lee SH, Kerff F, Chereau D, Ferron F, Klug A, Dominguez R (2007) Structural basis for the actin-binding function of missing-in-metastasis. Structure 15(2): 145-155.

Lee YG, Macoska JA, Korenchuk S, Pienta KJ (2002) MIM, a potential metastasis suppressor gene in bladder cancer. Neoplasia 4(4): 291-294.

Lin J, Liu J, Wang Y, Zhu J, Zhou K, Smith N, Zhan X (2005) Differential regulation of cortactin and N-WASP-mediated actin polymerization by missing in metastasis (MIM) protein. Oncogene 24(12): 2059-2066.

Liu K, Wang G, Ding H, Chen Y, Yu G, Wang J (2010) Downregulation of metastasis suppressor 1(MTSS1) is associated with nodal metastasis and poor outcome in Chinese patients with gastric cancer. BMC Cancer 10: 428.

Loberg RD, Neeley CK, Adam-Day LL, Fridman St Y, John LN, Nixdorf S, Jackson P, Kalikin LM, Pienta KJ (2005) Differential expression analysis of MIM (MTSS1) splice variants and a functional role of MIM in prostate cancer cell biology. Int J Oncol 26(6): 1699-1705.

Ma S, Guan XY, Lee TK, Chan KW (2007) Clinicopathological significance of missing in metastasis B expression in hepatocellular carcinoma. Hum Pathol 38(8): 1201-1206.

Mattila PK, Pykalainen A, Saarikangas J, Paavilainen VO, Vihinen H, Jokitalo E, Lappalainen P (2007) Missing-in-metastasis and IRSp53 deform PI(4,5)P2-rich membranes by an inverse BAR domain-like mechanism. J Cell Biol 176(7): 953-964.

Mattila PK, Salminen M, Yamashiro T, Lappalainen P (2003) Mouse MIM, a tissue-specific regulator of cytoskeletal dynamics, interacts with ATP-actin monomers through its C-terminal WH2 domain. J Biol Chem 278(10): 8452-8459.

Mertz KD, Pathria G, Wagner C, Saarikangas J, Sboner A, Romanov J, Gschaider M, Lenz F, Neumann F, Schreiner W, Nemethova M,
Glassmann A, Lappalainen P, Stingl G, Small JV, Fink D, Chin L, Wagner SN (2014) MTSS1 is a metastasis driver in a subset of human melanomas. Nat Commun 5: 3465.

Pao W (2012) New approaches to targeted therapy in lung cancer. Proc Am Thorac Soc 9(2): 72-73.

Pao W, Girard N (2011) New driver mutations in non-small-cell lung cancer. Lancet Oncol 12(2): 175-180.

Pao W, Iafrate AJ, Su Z (2011) Genetically informed lung cancer medicine. $J$ Pathol 223(2): 230-240.

Pao W, Kris MG, Iafrate AJ, Ladanyi M, Janne PA, Wistuba II, Miake-Lye R, Herbst RS, Carbone DP, Johnson BE, Lynch TJ (2009) Integration of molecular profiling into the lung cancer clinic. Clin Cancer Res 15(17): 5317-5322.

Parr C, Jiang WG (2009) Metastasis suppressor 1 (MTSS1) demonstrates prognostic value and anti-metastatic properties in breast cancer. Eur J Cancer 45(9): 1673-1683.

Scagliotti GV, Parikh P, von Pawel J, Biesma B, Vansteenkiste J, Manegold C, Serwatowski P, Gatzemeier U, Digumarti R, Zukin M, Lee JS, Mellemgaard A, Park K, Patil S, Rolski J, Goksel T, de Marinis F, Simms L, Sugarman KP, Gandara D (2008) Phase III study comparing cisplatin plus gemcitabine with cisplatin plus pemetrexed in chemotherapy-naive patients with advanced-stage non-small-cell lung cancer. J Clin Oncol 26(21): 3543-3551.

Sobin LH, Gospodarowicz MK, Wittekind C (2009) TNM Classification of Malignant Tumours (UICC International Union Against Cancer), 7th edn. John Wiley \& Sons: Chichester.

Travis WD, Brambilla E, Mueller-Hermelink HK, Harris CC (eds) (2004) Tumours of the Lung, Pleura, Thymus and Heart. IARCPress: Lyon.

Wang F, Liu Y, Zhang H (2013) Loss of MTSS1 expression is an independent prognostic factor for Hilar cholangiocarcinoma. Pathol Oncol Res 19(4): 815-820.

Wang Y, Liu J, Smith E, Zhou K, Liao J, Yang GY, Tan M, Zhan X (2007) Downregulation of missing in metastasis gene (MIM) is associated with the progression of bladder transitional carcinomas. Cancer Invest 25(2): 79-86.

Woodings JA, Sharp SJ, Machesky LM (2003) MIM-B, a putative metastasis suppressor protein, binds to actin and to protein tyrosine phosphatase delta. Biochem J 371(Pt 2): 463-471.

Xie F, Ye L, Chen J, Wu N, Zhang Z, Yang Y, Zhang L, Jiang WG (2011a) The impact of Metastasis Suppressor-1, MTSS1, on oesophageal squamous cell carcinoma and its clinical significance. J Transl Med 9: 95.

Xie F, Ye L, Ta M, Zhang L, Jiang WG (2011b) MTSS1: a multifunctional protein and its role in cancer invasion and metastasis. Front Biosci (Scholar edn) 3: 621-631.

Zhong J, Shaik S, Wan L, Tron AE, Wang Z, Sun L, Inuzuka H, Wei W (2013) SCF beta-TRCP targets MTSS1 for ubiquitination-mediated destruction to regulate cancer cell proliferation and migration. Oncotarget 4(12): 2339-2353.

This work is published under the standard license to publish agreement. After 12 months the work will become freely available and the license terms will switch to a Creative Commons AttributionNonCommercial-Share Alike 4.0 Unported License. 